\title{
Pattern of Newborn care and associated Health Problems among home delivered children
}

\author{
Singh JK ${ }^{1}$, Rauniyar $\mathrm{P}^{2}$, Gautam $\mathrm{D}^{3}$ \\ ${ }^{1}$ Department of Community Medicine, Janaki Medical College, Janakpur, Nepal. \\ ${ }^{2}$ Eastern Regional Health Directorate, Dhankuta \\ ${ }^{3}$ IYCF and Bal Vita Promotion Program, Max Pro, Kathmandu, Nepal
}

\begin{abstract}
Background and Objectives: Newborn Care practices during neonatal period contribute to risk of mortality and morbidity. It is estimated that in Nepal nearly 50,000 children under one year of age die every twelve months. This study aims to identify newborn care and practices in rural area in the study population.
\end{abstract}

Methodology: 248 mothers having children of age $<6$ months having delivery at home were selected from ten VDCs of Sunsari district using multistage random sampling. Standardized questionnaire were filled through interview with mothers / female head of the family who assisted the delivery. Data were analyzed by using statistical package for social sciences (SPSS) version 17. Chi-square test was conducted and p-value $<0.05$ considered as statistically significant.

Results: More than half (53.6\%) of the newborns were assisted with Clean Home Delivery Kit. However, only $32.6 \%$ of the newborn babies applied antiseptic disinfectant to umbilical stump. Majority (76.6\%) of the newborns bathed within 24 hour after birth. Less than half of respondents (41.9\%) started breast feeding within 1 hour of birth and majority of the respondents (82.7\%) fed colostrums to the newborn. Majority (37.9\%) of children suffered from Acute Respiratory tract Infection, jaundice, redness and discharge around the cord, skin rashes and eye discharge. The methods used to make room warm was significantly associated $\left(\chi^{2}=\right.$ $13.68, p$ - value $=0.001$ ) with the occurrence of ARI. Materials applied for dressing of cord was significantly associated with problems of cord in babies $\left(\chi^{2}=10.89, \quad p\right.$ - value $\left.=0.004\right)$. Discharge from eye was found more among the babies who applied kajal however it was statistically insignificant. $\left(\chi^{2}=0.60 \mathrm{p}=0.439\right)$.

Conclusion: High-risk traditional newborn care practices are common and need to be addressed.

Keywords: New born, Care of Cord, Home delivery, TBA

\section{INTRODUCTION}

Newborn Care practices during neonatal period contribute to risk of mortality and morbidity. Newborn mortality is one of the world's most neglected health problems [1]. Globally 3.9 million neonatal deaths constitute $36 \%$ of under-five child deaths [2]. 
About $98 \%$ of newborn deaths occur in developing countries, where most newborns deaths occur at home. The average neonatal mortality rate in developing countries is over eight times $(33 / 1000$ live births $)$ that prevailing in developed countries $(4 / 1000$ live births) [3]. In Nepal infant and neonatal mortality rate is very high i.e. IMR is $48 / 1000$ live births; NMR is 33/1000 live births and perinatal mortality rate is $45 / 1000$ live births [4]. It is estimated that in Nepal nearly 50,000 children under one year of age die every twelve months. Infant mortality has declined by $41 \%$ over the 15 year period from 82 deaths per 1000 live births to 48. The corresponding decline in the neonatal mortality over the 15 year period is only $33 \%$ [5]. Thus the newborn health challenge faced by Nepal is more voluminous, more diverse and more formidable. Newborn health is the key to child survival especially for a developing country like Nepal. Addressing infant mortality requires a continuity in the elements of care, which is lacking in many settings/communities with care for the neonate often receiving little attention in either maternal or child health programmes. The greatest gap in care often occurs during the critical first week of life when most neonatal and maternal deaths occur, usually at home and without any contact with the formal health sector. This study will be helpful to identify newborn care and practices in rural area in the study population, which will help in checking the infant morbidity and mortality.

\section{MATERIAL AND METHODS}

This is a cross-sectional study was carried out in 9 village development committee (VDC) of Sunsari district. Two hundred and fourty eight mothers having children aged $<6$ months delivered at home were selected using multistage random sampling and standardized questionnaire was administrate through interview among them (or /and female head of the family who assisted her delivery). Simple Random sampling was done to select the VDC with the help of DDC record and convenience and feasible sample was taken till the required number of sample was achieved with the help of FCHVs and TBAs in each VDC. Sample Size was calculated by using formula, $n=z^{2} p q / e^{2}$. Where, Prevalence of ARI in neonates is 20\%) and $\mathrm{z}=1.96$ at 95\% confidence level with allowable error $5 \%$. Respondents were fully informed and verbal consent was taken before data collection and privacy and confidentially was maintained. Data were analyzed by using statistical package for social sciences (SPSS) version 17 for windows. Chi-square test was conducted and p-value less than 0.05 considered as statistically significant.

\section{RESULTS}

Table1 shows background characteristics of the respondents. Majority of the respondents (36.7\%) were in the age group of 20-24 years and about $19 \%$ were teenagers. Among all the respondents, maximum (39.5\%) were dalit followed by $(37.5 \%)$ and $(22.6 \%)$ from non dalit castes and Upper caste group respectively. Proportions of illiterate mothers were high (61.7\%) and majority of respondents (94.4\%) engaged in household work and very few $(0.8 \%)$ were labour. Proportion of female newborn babies was high $(58.9 \%)$ than the male. Only $31.5 \%$ of deliveries were assisted by trained health worker at home followed by traditional birth attended (26.2\%) and majority (37.5\%) were attended by family member themselves. 


\begin{tabular}{|c|c|c|}
\hline $\begin{array}{l}\text { Table-1: Background } \\
\text { characteristics of the respondent }\end{array}$ & Frequency & Percent \\
\hline \multicolumn{3}{|l|}{ Age distribution (in Years) } \\
\hline $15-19$ & 47 & 19.0 \\
\hline $20-24$ & 91 & 36.7 \\
\hline $25-29$ & 61 & 24.6 \\
\hline $30-34$ & 49 & 19.8 \\
\hline \multicolumn{3}{|l|}{ Caste-wise distribution * } \\
\hline SC & 99 & 39.9 \\
\hline OBC & 93 & 37.5 \\
\hline General & 56 & 22.6 \\
\hline \multicolumn{3}{|l|}{ Educational Status } \\
\hline Illiterate & 153 & 61.7 \\
\hline Literate & 95 & 38.3 \\
\hline \multicolumn{3}{|l|}{ Occupation } \\
\hline Household & 234 & 94.4 \\
\hline Work & & \\
\hline Agriculture & 12 & 4.8 \\
\hline Labour & 2 & 0.8 \\
\hline \multicolumn{3}{|l|}{$\begin{array}{l}\text { Sex of the last } \\
\text { child }\end{array}$} \\
\hline Female & 146 & 58.9 \\
\hline Male & 102 & 41.1 \\
\hline \multicolumn{3}{|l|}{ Attendant at home Delivery } \\
\hline $\begin{array}{l}\text { Family } \\
\text { member }\end{array}$ & 93 & 37.5 \\
\hline Neighbour & 12 & 4.8 \\
\hline Traditional & 65 & 26.2 \\
\hline Birth & & \\
\hline Attended & & \\
\hline Trained & 78 & 31.5 \\
\hline Health & & \\
\hline Worker & & \\
\hline Total & 248 & 100.0 \\
\hline
\end{tabular}

*Schedule Caste (SC): Dalit, Other Backward Caste (OBC): Non Dalit Tarai Castes, General: Upper Caste Group.

Table 2 shows that more than half $(53.6 \%)$ of the newborns were assisted with Clean Home Delivery kit . Only $32.6 \%$ of the newborn babies applied antiseptic disinfectant to umbilical stump and $46.8 \%$ of the newborn babies applied mustered oil with turmeric.

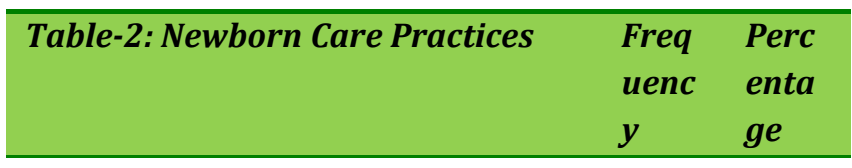

Utilisation of delivery kit

$\begin{array}{lll}\text { Yes } & 133 & 53.6 \\ \text { No } & 115 & 46.4\end{array}$

Care of Cord (Dressing applied)

$\begin{array}{lll}\begin{array}{l}\text { Oil and } \\ \text { turmeric }\end{array} & 116 & 46.8 \\ \text { Antiseptic } & 81 & 32.6 \\ \text { Nothing } & 51 & 20.6\end{array}$

Time of bathing the baby after birth

$\begin{array}{lcc}\leq 24 \text { hour } & 190 & 76.6 \\ >24 \text { hour } & 58 & 23.4\end{array}$

Method to make room warm

$\begin{array}{lcc}\text { Fire } & 157 & 63.3 \\ \begin{array}{l}\text { Coal/Cow } \\ \text { dung cake }\end{array} & 66 & 26.6 \\ \begin{array}{l}\text { Heater } \\ \text { Heat }\end{array} & 25 & 10.1\end{array}$

Initiation of breast feeding

Colostrum feeding

$\leq 1$ hour $\quad 104 \quad 41.9$

$>1$ hours $\quad 144 \quad 58.1$

$\begin{array}{lcc}\text { No } & 43 & 17.3\end{array}$

Prelacteal feeding

$\begin{array}{lcc}\text { No } & 221 & 89.1 \\ \text { Yes } & 27 & 10.9\end{array}$

Application of oil inside the baby's orifice

$\begin{array}{lcc}\text { No } & 41 & 16.5 \\ \text { Yes } & 207 & 83.5\end{array}$

Application of Kajal in Eye

\begin{tabular}{lccc} 
No & 43 & 17.3 \\
Yes & 205 & 82.7 \\
\hline Total & 248 & 100 \\
\hline
\end{tabular}

Further, in this study majority (76.6\%) of the newborns bathed within 24 hour after birth and few (23.4\%) after 24 hours. Majority $(63.3 \%)$ of the respondents warmed their room by fire followed by (26.6\%) with coal and cow dung cake and very few (10.1\%) used heater to make room warm. Less than half of respondents (41.9\%) started breast feeding within 1 hour of birth and majority of 
the respondents $(82.7 \%)$ fed colostrums to the newborn. Very few (10.9\%) started prelacteal feeding with honey and cow's milk. Maximum 83.5\% applied oil inside ear, nose and urethral orifice to the babies during massage and maximum $(82.7 \%)$ applied kajal in eye.

Around half of babies (48.4\%) did not suffer from any type of health problems and remaining suffered from different health problems. Among them highest was the ARI (37.9\%) followed by Redness and discharge around the cord (14.11\%), Eye discharge (12.9\%), Jaundice (4.03\%), and Skin rashes (Blister) (3.62\%).

\begin{tabular}{lcc}
\hline $\begin{array}{l}\text { Table-3: Type of health } \\
\text { problems to the baby* }\end{array}$ & $\begin{array}{l}\text { Freq } \\
\text { uenc } \\
\text { y }\end{array}$ & $\begin{array}{l}\text { Perce } \\
\text { ntage }\end{array}$ \\
\hline ARI & 94 & 37.90 \\
Discharge around the & 35 & \\
Cord & & 14.11 \\
Eye discharge & 32 & 12.90 \\
Jaundice & 10 & 4.03 \\
Skin Rashes (Blister) & 9 & 3.62 \\
None & 120 & 48.40 \\
\hline Total & 248 & 100 \\
\hline
\end{tabular}

*Multiple Responses

Table 4 shows the associated health problems of newborns in relation to different factors. Approximately 38\% of babies suffered from ARI and $14.11 \%$ babies had discharge from cord which was associated with the materials used for warming room $\left(\chi^{2}=13.68, \mathrm{p}\right.$ - value $=$ $0.001)$ and material applied on cord cut $\left(\chi^{2}=\right.$ $10.89, \mathrm{p}$ - value $=0.004$ ) respectively. Out of 43 babies who did not apply kajal on eye, 9.3\% had eye discharge where as out of 205 who apply kajal , $13.7 \%$ of babies had discharge from eye. $\left(\chi^{2}=0.60, \quad p\right.$ - value $=$ 0.439)

\begin{tabular}{|c|c|c|}
\hline \multicolumn{3}{|c|}{$\begin{array}{l}\text { Table-4: Newborn Care Practices and associated } \\
\text { Problems }\end{array}$} \\
\hline & \multicolumn{2}{|c|}{ Health Problems } \\
\hline Practices & Yes & No \\
\hline \multicolumn{3}{|c|}{ Dressing applied and discharge from Cord } \\
\hline Nothing & $9(17.6)$ & $42(82.4)$ \\
\hline Antiseptic & $3(3.7)$ & $78(96.3)$ \\
\hline & & \\
\hline turmeric & $23(19.8)$ & $93(80.2)$ \\
\hline \multicolumn{3}{|c|}{$\chi^{2}=10.89, \quad p-$ value $=0.004$} \\
\hline \multicolumn{3}{|c|}{ Method to make room warm and ARI } \\
\hline Heater & $3(12.0)$ & $22(88.0)$ \\
\hline $\begin{array}{l}\text { Coal/Cow } \\
\text { dung cake }\end{array}$ & $19(28.8)$ & $47(71.2)$ \\
\hline Fire & $72(45.9)$ & $85(54.1)$ \\
\hline \multicolumn{3}{|c|}{$\chi^{2}=13.68, p-$ value $=0.001$} \\
\hline \multicolumn{3}{|c|}{ Application of Kajal and discharge from Eye } \\
\hline Yes & $28(13.7)$ & $177(86.3)$ \\
\hline No & $4(9.3)$ & $39(90.7)$ \\
\hline \multicolumn{3}{|c|}{$\chi^{2}=0.60, \quad p$ - value $=0.439$} \\
\hline
\end{tabular}

\section{DISCUSSION}

Majority of respondents were in the age group of 20-24 years but 19\% was below 19 years. This shows the tradition of the early marriage in the community. Majority of the respondents were from Scheduled caste and few from general caste. More than half of the respondents were illiterate. Most of respondents were engaged in household work and very few of them were engaged in labour because of poverty. Proportion of female newborn babies was high and very few deliveries were assisted by trained health worker.

In this study more than half of birth attended using Clean Home Delivery Kit (CHDK). A study by Care Nepal (2003) showed that around $16 \%$ of mothers used a Safer Home Delivery Kit (SHDK) during the last delivery 
[7] and a study by Global Health (2005) reported that the kit has significant impact in reducing rates of infection. Newborns of mothers who used the clean delivery kit were about 13 times less likely to develop cord infection than infants whose mothers did not use the kit. Women who used the kit were about 3 times less likely to develop puerperal sepsis than women who did not use the kit.

Only one third of the births applied antiseptic disinfectant to umbilical stump and approximately half applied oil and turmeric but few births applied nothing to it. In a similar study by Alam et al. (2008) in Bangladesh found that the most common substances used on the cord were turmeric (83\%) and rest applied mustered oil, ash, coconut oil, ginger and chewed rice [8]. It was found that most of children were given bath within 24 hours of birth. Similar study by Barnette and azad (2006) in Bangladesh reported that only $44 \%$ of the infants were bathed immediately after delivery. [9] This condition climatic condition in Nepal put the infants to the high risk of hypothermia. Most of respondents warming their the room by burning firewood followed by coal or cow dung cake which is responsible for smoking environment in the room leading to high risk of respiratory problems to whole the mother and children and even put them at the high risk of morbidity and mortality. Few women started breast feeding within one hour of birth. Study by Sreeramreddy et. al. (2007) in Nepal found that initiation rates of breastfeeding were $57.9 \%$ within one hour and 42.2 $\%$ within 24 hours [10]. Similar study by Orisin et. al. (2002) in rural Nepal found that $63 \%$ of babies were breast fed within an hour of birth [11]. Most of the women fed colostrum to the newborn children and few did not saying that colostrum is dirty milk, traditional practice, baby cannot digest. A study conducted by Yadav (2007) on traditional practices in newborn care in Nepal shows that colostrum is regarded as dirty milk in some communities, and babies were fed with cow or goat milk immediately after birth for the popular belief that it will make the baby become more intelligent. [12] Similar study by Sreeramreddy et. al. (2007) in Nepal found that about $10.8 \%$ mothers did not feed colostrums to their babies. Another study by Barnette and azad (2006) in Bangladesh found that $85 \%$ of women said that the first milk feed given to their newborn infants [9]. The mother who did not start breast feeding early gave to prelacteal feeding to their children were given as Prelacteal feeds honey, cow's milk and others mother milk. Similar study done by Sreeramreddy et. al. (2007) in Nepal reported that Pre lacteal feeds were given to $15.2 \%$ newborns [10]. Another Similar study by Orisin et. al. (2002) in Nepal found that a taste of clarified butter (ghee), sugar, or honey was given before feeding began $12 \%$ [11]. Majority of respondents applied oil inside ear, nose and urethral orifice to the children, $1 / 3^{\text {rd }}$ applied only in ear and few applied only in nose. These are harmful practices which lead different problems like infection and allergies in children so these practices should be avoid in communities. Application of kajal was also common practice. It was found that nearly half of the children did not suffer from any type of health problems, more than $1 / 4^{\text {th }}$ suffered from ARI and few suffered from jaundice, redness and discharge around the cord, skin rashes and eye discharge. These are the great problems of communities and country which increase infant morbidity and mortality. This may cause high in IMR. There are several factors that are responsible for problem of ARI including cow dung cake used to make room warm. Statistically significant 
association was found between method to make room warm and occurrence of ARI $(\mathrm{p}=0.001)$. Materials applied for dressing of cord had also significant role on problems of cord in babies $(\mathrm{p}=0.004)$. Most of mothers applied kajal in eye of the babies to protect from ghost/ evil eye and for beauty which is harmful practice and lead to eye infection. However, there was no statistically significant association between effect on eye and application of kajal $(\mathrm{p}=0.439)$.

\section{CONCLUSION}

Women know little about the importance of delivery by a skilled attendant or of guidelines for care of newborn children. From the analysis of the data it can be concluded that traditional child care practices have significant effect on health of the baby. It takes huge efforts to change this tradition. The high-risk traditional newborn care practices like early bathing, mustard oil application on the cord and orifices and Prelacteal feeding need to be addressed by culturally acceptable community based health education programmes and activities which play an important role in making community aware of the healthy practices

\section{ACKNOWLEDGEMENTS}

Authors wish to acknowledge the support of all the participants of the study.

\section{REFERENCES}

1. Black R. E., Morris, Bryce J (2003). Where \& why are 10 million children dying every year? Lancet. 361:2226-2234.

2. Dadhich J. P, Paul V. (2004). State of India's Newborns. Editors : National Neonatology Forum and Save the Children/US Nov 2004 New Delhi/Washington, DC

3. Parlato R., Darmstadt G., Tinker A., (2004): Qualitative Research to Improve Newborn Care
Practices. Saving Newborn Lives: Tools for Newborn Health.Washington DC.

4. MoH, Government of Nepal/ New Era/ORC Macro, 2006. Nepal Demographic and Health Survey, Kathmandu, 2006.

5. Family health division, DoHS, MoHP, Nepal, Government, National Neonatal Health Strategy, 2004.

6. Lawn JE, Cousens S, Zupan J.. The Executive Summary of the Lancet Neonatal Survival Series. The Lancet 2005; 365: 891-900.

7. Care Nepal. (2003). Child Survival in Kanchanpur district, Nepal.

8. Alam MA, Ali NA, Sultana N et al. Newborn umbilical cord and skin care in sylhet district, Bangladesh: implications for the promotion of umbilical cord cleansingwith topical chlorhexidine. J Perinatol 2008;Dec 28 (Suppl 2):S61-8.

9. Barnett S, Azad K, Barua S, et. al.. Maternal and Newborn-care Practices during Pregnancy, Childbirth, and the Postnatal Period: A Comparison in Three Rural Districts in Bangladesh. BMJ Health Popul Nutr. 2006; 24(4):394-402

10. Sreeramareddy C, Joshi H, Sreekumaran B, Giri S, Chuni N. Home delivery and newborn care practices among urban women in western Nepal: a questionnaire survey. BMC Pregnancy Childbirth 2006; Aug 23: 6:27.

11. Orisin K, Tumbahanphe D. Cross sectional, community based study of care of newborn infants in Nepal. BMJ 2002; 325: 1063-1067.

12. Yadav S. (2007). Newborn care: traditional practices in Nepal. Archive.student.bmj.Com/ issues /07/09/life/308. 